\title{
THE AUTHENTIC AND INAUTHENTIC SPORT IN THE HERMENEUTIC AND PHENOMENOLOGICAL PERSPECTIVES
}

\author{
Ivo Jirásek ${ }^{1}$, Josef Oborný ${ }^{2}$, Emanuel Hurych ${ }^{3}$ \\ ${ }^{I}$ Faculty of Physical Culture, Palacký University, Olomouc, Czech Republic; \\ ${ }^{2}$ Faculty of Physical Education and Sport, Komenský University, Bratislava, Slovak Republic; \\ ${ }^{3}$ Faculty of Sport Studies, Masaryk Universtiy, Brno, Czech Republic
}

\begin{abstract}
Summary: The philosophical concept of hermeneutics presents the opposite pole of human mental activities than positivism. Phenomenology, together with hermeneutics, also presents a kind of opposition to the positivistic reduction of learning the world. This paper focuses on the topic of authenticity of sport from these two (hermeneutic and phenomenological) approaches. As a basic theoretical platform Martin Heidegger's book Time and Being is used. The authors develop a specific kind of categorization of the social groups engaged in sport events via the ancient concepts of “TECHNÉ ATHLETIKÉ" and "TECHNÉ GYMNASTIKÉ". Two different phenomena: sport and "sport" are examined within the next part of the paper. There are some reasons mentioned in conclusions coming from the hermeneutic and phenomenological approach which help us to understand and accept the opinion that a kind of return to "techné gymnastiké" can support the authentic modes of being in human approach to sport.
\end{abstract}

Keywords: Sport; “sport”; TECHNÉ GYMNASTIKÉ; TECHNÉ ATHLETIKÉ; authenticity

DOI 10.2478/afepuc-2018-0001

(C) Acta Facultatis Educationis Physicae Universitatis Comenianae 


\section{Introduction}

The philosophical concepts of hermeneutics and phenomenology radically differ from positivism. While positivism focuses on the facts which are set in the objective way (everything which can be measured, weighted and expressed in the quantitative outputs of the scientific research), hermeneutics uses qualitative approaches of the scientific research.

The aim of hermeneutics is not to give an explanation but to reach understanding. Phenomenology also (together with hermeneutics) presents a kind of opposition to the positivistic reduction of learning the world. The way of thinking which is based on examining phenomena (from Greek FAINOMENON = phenomenon, occurrence) is in some contrast to Immanuel Kant's philosophy which distinguishes between the phenomenal world of knowable things and the noumenal world which is not accessible for our experience. Phenomenology perceives phenomena of the world which do not lead to some incognizable substances but to the eidos which appears and can be examined by a specific method.

The contemporary phenomenological stream in philosophy comes from the original ideas of Franz Brentano and Edmund Husserl. Phenomenology was then developed with the concept of fundamental ontology founded by Martin Heidegger. However, the phenomenological method started to be applied not just in philosophy but in many social sciences and humanities. It is often used in sociology (Costelloe 1996), psychology (Journal of Phenomenological Psychology), aesthetics (Journal of Aesthetics and Phenomenology), jurisprudence (Kinneging 2001), or in some partial social analyses in postmodernism (Murphy 1989).

Within philosophical analyses of human movement (and sport, especially) phenomenology presents a very often used term. Many authors mention that it opens a new space for better understanding of sport and that philosophy of sport expects and welcomes this kind of analyses (Meier, 1983; Osterhaudt, 1974, 1978; Weiss, 1982). Unfortunately, some experts in kinanthropology are not patient and careful enough to get learnt the original philosophical reflections more in detail. They often use just secondary sources (Kerry \& Armour, 2000). That is the main reason why the core of the phenomenological method is not understood properly. There are three main kinds of errors here: the confusion of phenomenology with immediacy, with an epistemologically subjectivist stance (phenomenalism), and with empirical research oriented towards objects in the world (Halák, Jirásek \& Nesti 2014). 


\section{AUTHENTICITY IN MARTIN HEIDEGGER'S CONCEPT}

One of the significant impulses, which can be brought by phenomenology into philosophical kinanthropology, is the topic of authenticity (from a Greek AUTHENTES = handmade created; credibility, or originality). To keep the meaning under which authenticity is understood in the philosophical context, we should mention Heidegger's work of Being and Time. This book focuses on the difference between the ontical and ontological characteristics of being. Sometimes it is very difficult to express the original German ideas in English. According to Heidegger, metaphysics has been exploring more through the ontic than the ontologic attributes of being. The ontologic characteristics have been omitted because of focus on the ontic analyses of being. The differentiation between the way how the entity exists (the ontic being) and the fact that it exists (the ontologic being) enables us to reach a better understanding of subjectivity and intersubjectivity of being, despite some possible confusions in the explanations of these approaches (O'Brien 2014). If ontic being is presented by any existing entity, the ontologic being does not mean anything objective and material, it is a projection (or simply an attribute of the ontic being). The difference between the ontic and ontologic touches any human being although not everybody really asks about this topic.

The ontologic being can be considered after we start to perceive that existence of the ontic being is not obvious. That means, after we get a surprise from the existence and after we ask: "why is there something rather than nothing?" This question is generally considered to be an important philosophical problem, as an American writer and philosopher Jim Holt tries to describe and explore in his book Why Does the World Exist (Holt 2012). The ontologic being grants a guarantee to any ontic being that it really exists. That is why some other thinkable ontic beings (stones, trees, animals etc.) definitely occur but they do not exist in the philosophical sense of existence (their being does not contain a question for themselves).

So, we are included in the question about our being. We ask because of ourselves and from the position of our situation. And, if our being is temporal, then the categorial determination of all human experience is done by its temporality. Our being is included in the present. The past means throwingness (we are thrown into the life situations which were not selected by us). The future means the possibility of scheduling (we can decide what we focus on and which way we want to live in).

The authentic existence (the way of life which is not limited with mere caring of things) is conscious of our mortality (being-to-death) and our open possibility to be 
"ourselves". The awareness of terminality of our being, leaning out to "nothingness" and selftranscendence - these conditions present a possibility to penetrate deeper layers of our being, to reach the level of the authentic existence.

The authentic possibility of being supposes being-towards-death as a significant possibility of Dasein (Being-in-the-World), which means a possibility to be focused on realization of this feature of Dasein in the modus of expectation. This way of being (existence as being-towards-death) is accessible just for human: an animal perishes, just man dies in the context of being-towards-death. Some ability to leave the inauthentic way of being ("the They", in German original it is "Das Man") means the ability to turn to one-self (Heidegger 2008).

The authentic experience is not related to care of corporeal things but it gives reference about transcendence to future - to our final definiteness. The perception of our mortality and relating to our very last limit enable us to schedule our possibilities of being. Any experience which is chosen this way gives evidence about the way how we manage our possibilities and how we exist in the authentic way. Only this terminality (knowledge of existence of our death) can help us to reach a better understanding of ourselves and a possibility to recognize the modus of our freedom. We are free in our being and in a care of it, in the possibilities how to schedule our lives, and in the modes of experience which we choose. If we fall into the "world of things" (a focus on "what is spoken", "what is on", "what is recommended" - that means falling into "the They") we could not consider the "authentic" experience because we would not be related to the ontologic being but just to the ontic one.

The essential parts of the inauthentic being (and the inauthentic experience) are mediocrity, irresponsibility and indifference to the others. The authentic experience is characterised by a deep perception of terminality of the person in which this person (through the possibility to be one-self) intensifies his/her identity of thinking, speaking and acting. This helps to translation from impersonal superficiality (expressing in taking care of a subjective way of being) towards a personal responsibility for scheduling the future.

The existential feature of this "the They" is mediocrity. An average characteristic of what is done, what is worn, what is considered to be successful or unsuccessful. Mediocrity presents delimitation of (very personal) individuality, significant singularity and exceptionality under influence of the impersonal "the They". The tyranny of fashion, advertisements, markets or a bureaucratic power which is presented in the contemporary Euro-American society documents a loss of authenticity. It is not ordered or wished by any concrete individual (even if there are some people who like these situations and use them for 
their profit). It is a sign of dominance of something impersonal and indefinite. Through common everydayness we stay in the mode of indefinity. The intentional being "One's Self" (Heidegger, 2008) presents a significant feature of authenticity. However, there is a key question here: How to find being One's Self? Or, how to accomplish the famous instruction inscribed in the pronaos of the Temple of Apollo at Delphi which says "gnothi seauton", translated in English as "know thyself"? (Thompson \& Matheson 2007).

\section{THE ANCIENT CONCEPTS OF MOVEMENT CULTURE - "TECHNÉ GYMNASTIKÉ" AND “TECHNÉ ATHLETIKÉ"}

One of the possibilities how to overcome the impersonal "the They" towards the authentic mode of being can be provided by movement culture (including sport activities). The Greek ancient culture knew two important terms used in the context of sport which characterize a relation of the ancient Greeks to body and physicality: gymnastics and athletics. (Here it should be stressed that a modern interpretation and understanding of the essence of those two sports gymnastics and athletics do not properly reflect the difference described in the text.) The ancient gymnastics could be perceived as a harmony of sport and movement culture (it means sport without any attribute), and as the authentic mode of sport influenced by a natural human power and its harmonical development.

"TECHNÉ GYMNASTIKÉ" was a kind of art in spite of the fact that it was based on physical skills. Omitting the fact that the sportsmen were naked (and that their nakedness supported the aesthetical understanding of motion and expressing of beauty), we can observe the reflection of the ideals of "TECHNÉ GYMNASTIKÉ" in many forms of modern recreational (or some competitive) sports. Harmony in human movement, perfectionalism and beauty of motion has been still presenting a very important motive there (Reid 2012a). This kind of perception and realization of those ideals can be labelled here as sport and we will understand this kind of movement activity as the authentic sport.

On the contrary, athletics was characterized by an effort to develop some parts of human body only without taking account of the holistic approach. The unilateral focus on performance (expressed in the form of a result) aimed against the idea of kalokagathia and overstepped the concept of movement culture and care of human body. Although this activity was also labelled as an art - "TECHNÉ ATHLÉTIKÉ" (the art of athletics) the unilateral characteristics of it is obvious. The same features can be observed in the case of modern professional sport (the elite sport) which is accompanied by corruption and protectionism (as well as "TECHNÉ ATHLÉTIKÉ" in the ancient Greece). 
Some professional sportsmen in the period of Hellenism focused, instead of cultivation of the mind via physical exercises, on developing those parts of their bodies which were necessary for getting victory or breaking the record. In this effort, they were very like many modern sportsmen/women. As well as the ancient boxers, wrestlers, or pankrationists, many contemporary elite sportsmen/women neglect some body deformations. We should reject this approach, in the same way as did it the ancient poets, physicians and philosophers. That is why we will use the term "sport" for those activities and we will understand them as the inauthentic mode of movement activity.

Could we delimit the exact borders between sport and "sport"? We argue that our effort to reach this distinction is very problematic because this kind of delimitation is merging, confusing and blending. There is the only chance to follow the meaning and sense of the activities. The nature of the meaning which is devoted to movement activities answers the question whether we can speak about the world of sport or the world of "sport". There is quite a broad range of literature devoted to the problems of meaning in the world of movement activities (Lawrence 1989; Mandelbaum 2004; Pawlenka 2005; Kluck 2007; Cléret \& McNamee 2012; Balçikanli 2014). In conclusion: the major values are included in the ideas of kalokagathia, areté, or fair play. Even the agonal character of competition, rivalry and strong competitiveness cannot break the ethical anchoring of human behaviour here. The values are concentrated around a rich individual experience and beauty of human movement.

However, which kind of values can we see in the other sphere of human movement the world of "sport"? Here we can consider a long tradition of the ancient sport where we were meeting many different motives for engaging in sport activities. We could also meet different expectations of what those events could mean for any individual (Reid 2012b).

\section{The categorization of the social groups engaged in sport events}

There can be established four concrete kinds of meanings here laid in some activities which are accompanied by a strong desire for success, attention of public, unilateral load and financial transactions. The categorization is based on the engaged social groups and their preferences:

\section{The Sportsmen}

Here we could divide this group more in detail and classify the sportsmen per their motivation: Professionals who take sport as an ordinary job, those for whom sport is a way of self-presentation, the other ones who want to postpone the human limits (or just their own 
ones), the individuals who look for the experience from the competition or the game, those who try to develop game strategies etc.

However, this kind of distinction is not relevant for our purposes. What is important is a kind of knowledge that for the sportsmen/women themselves can be very important of what kind their motivation is deciding (financial interests, self-presentation etc.) but for the meaning of the activity the kind of motivation presents just a marginal topic. The character of this group is minority. The motivation is not transferable to other groups. These modern heroes (stars, millionaires, objects of different fan clubs...) present and establish (through their sport activities) some possibilities how to develop a new meaning of movement activity which is related to their performance. Here new meanings appear and grow (via the sportsmen/women) which do not primarily belong to them and which differ motive by motive (per the way of answering the question why sportsmen/women accept challenges of "sport").

\section{The Spectators and Fans}

The participants of this group perceive "sport" as a show (spectacle), as an identification with a social group (club, team), as a form of spending their leisure time, or as a passive way of relaxing. Although it looks like the reactions of spectators and fans are decisive for the active sportsmen/women, this idea is much closer to illusion than to reality. Real interconnectedness and mutual dependence is, in fact, developed via the third group. The interest of spectators is to buy a spectacle and to pay for watching performance made by somebody else. The psychological and sociological aspects of this problem are very broad and they are described in detail within the literature devoted to the psychology of crowds (Le Bon 2009; Drury \& Scott 2015 etc.). However, it is obvious that without salesmen and businessmen the interests of spectators cannot be satisfied.

\section{The Businessmen}

They deal and trade with human performance and human bodies and they offer them (as goods) to some other people. In general, there is no difference whether some small sums of money are paid during a weekend village football match, or if millions or billions of dollars are paid for TV broadcasting of the big sport events. The meaning of "sport" for this group consists just in a maximal financial profit. This is the reason why managers and sport functionaries are successful if they have good results in selling and buying sportsmen. The commercials and advertisements become compulsory and urgent components of "sport". The businessmen who are directly connected with the sphere of "sport" are tied to many other financial and business subjects which are not interested in "sport" at all. However, the high number of spectators and fans present a great opportunity for them to develop their business. 
The offers of goods and services are not limited by business with sport instruments and equipment. They include a much broader spectrum of advertised and sold things (from drinks and food to cars, or even industrial buildings etc.). All of this is offered and sold within the events whose original sense should have consisted in the manifestation of beauty of human movement, fair sport competition and the ideals of harmonic personal development. For this group "sport" presents just background of their activities which can be easily replaced with any other settings where business can be handled.

\section{The Unbiassed Public}

The participants of this group give a meaning to "sport" by the fact that they do not attribute any special sense to it. There can appear some confusing points here, or misunderstandings and we can also meet some prejudice. The opinion of this group is often related to some clichés about the harmful effects of "sport" (a ball as a "round nonsense", wasting money on "useless things", "sport" as a highway to the "permanent invalidity" etc.). However, the unbiased public need not present just a lay community which is not interested in movement culture (of course, this situation is also quite often) but it can be consisted of the people who reject the practice of "TECHNÉ ATHLÉTIKÉ" and prefer "TECHNÉ GYMNASTIKÉ" - as an inspiring and profitable approach to human movement. These people can present the ones who very carefully distinguish between sport and "sport".

\section{Conclusions}

The authentic mode of sport is personalized by human being of a sportsman/woman and has got some essential attributes: subjectivity, creativity and playfulness. For this reason, the hypertrophic technologized management of the sportsmen/women by coaches can bring some negative effects. One of them can be a kind of hypostatization of a personality. This effect transforms a sportsman/woman into a "thinking thing" just practising a movement action. A high level of sport performance then can provide "just" a kind of pleasure and enjoyment coming from performance (in a form of the result) but not coming from sport activity itself, nor from a creative physicality of a sportsman/woman.

If we accept the idea that the substance of sport is formed by its ludity (playfulness), then the next question must be asked: Should a sportsman enjoy the play, or should he/she be just an object of the play which is ruled by somebody else? Here we can speak about some forms of dehonestation of sport (and "sport", especially). A typical feeling for these forms is 
alienation coming from impossibility of sportsmen/women to identify themselves with the realized sporting activity. For this reason, this activity cannot be considered as personal and is lacking in the intrinsic motivation.

The above described four cases of different approaches to "sport", interconnected and interpenetrated one with another, do not have much in common with the idea of the harmonic human development and with the idea of common care of body and soul. While sport presents a significant and essential part of movement culture, "sport" is uncultured. And, a human body presents in its context just a solid, in the mathematical (or geometrical) way of understanding.

However, we should not be satisfied with this statement. If we would be able to offer some other ways how to find better meanings of human movement, if we take meaningful care of our bodies and if we refuse to play the role of businessmen or goods in the world of "sport", we can return to "TECHNÉ GYMNASTIKÉ" and save the world of sport together with its ideals. Then we can develop and enrich the complex of movement culture. It presents a very strong imperative for our postmodern, consumeristic and sedentary society.

\section{References}

1. BALÇIKANLI, G. S., 2014. Fair Play in Professional Sports: Sportspersonship Orientations of Futsal Players. Fair Play. Journal of Sport: Philosophy, Ethics and Law. 2(1), 33-49.

2. CLÉRET, L. \& M. McNAMEE, 2012: Olympism, the Values of Sport, and the Will to Power: de Coubertin and Nietzsche Meet Eugenio Monti. Sport, Ethics and Philosophy. 6(2), 183-194.

3. COSTElloE, T. M., 1996. Between the subject and sociology: Alfred Schutz's phenomenology of the life-world. Human Studies. 19(3), 247-266.

4. DRURY, J. \& C. SCOTT, 2015. Crowds in the 21st Century: Perspectives from Contemporary Social Science. London, UK: Routledge. ISBN: 978-0415635905.

5. HALÁK, J., I. JIRÁSEK \& M. NESTI, 2014. Phenomenology is not phenomenalism. Is there such a thing as phenomenology of sport? Acta Gymnica. 44(2), 117-129. doi: 10.5507/ag.2014.012.

6. HEIDEGGER, M., 2008. Being and Time. Translated by John MacQuarrie \& Edward Robinson. New York: Harper \& Row Publishers. ISBN: 978-0061575594. 
7. HOLT, J., 2012. Why does the world exist. London, UK: Profile Books, Ltd.

8. KERRY, D. S., \& K. M. Armour, 2000. Sport sciences and the promise of phenomenology: Philosophy, method, and insight. Quest. 52(1), 1-17.

9. KINNEGING, A. M., 2001. Realist Phenomenology and the Foundations of Natural Law: The Vindication of the Moral Order in the Works of Scheler, Hartmann, and Hildebrand. The American Journal of Jurisprudence. 46(1), 257-275.

10. KLUCK, T., 2009. The Reason For Sports: A Christian Fanifesto. Chicago, IL: Moody Publishers. ISBN: 978-0802458360.

11. LAWRENCE A. W. (Ed.), 1989. Media, Sports and Society. Sage, Newbury Park. ISBN: 978-0803932449.

12. Le BONN, G., 2009. Psychology of Crowds. Southampton, UK: Sparkling Books Ltd. ISBN: 978-1907230080.

13. MANDELBAUM, M., 2004. The Meaning of Sports. New York, NY: Public Affairs.ISBN: 978-1586483302.

14. MEIER, K. V., 1983. A meditation on critical mass in the philosophy of sport. Journal of the Philosophy of Sport. 10(1), 8-20.

15. MURPHY, J. W., 1989. Postmodern Social Analysis and Criticism. New York, US: Greenwood Press. ISBN: 978-0313266836.

16. O'BRIEN, M., 2014. Leaping Ahead of Heidegger: Subjectivity and Intersubjectivity in Being and Time. International Journal of Philosophical Studies. 22(4), 489-490.

17. OSTERHAUDT, R. G., 1974. Modes of philosophic inquiry concerning sport: some reflections on method. Journal of the Philosophy of Sport. 1(1), 137-141.

18. OSTERHAUDT, R. G., 2078. The History and Philosophy of Sport: The Re-unification of Once Separated Opposites. Journal of the Philosophy of Sport. 5(1), 71-76.

19. PAWLENKA, C., 2005. The Idea of Fairness: A General Ethical Concept or One Particular to Sports Ethics. Journal of the Philosophy of Sport. 32(1), 49-64.

20. REID, H., 2012a. Athletic Beauty in Classical Greece: A Philosophical View. Journal of the Philosophy of Sport. 39(2), 1-17.

21. REID, H., 2012b. The Political Heritage of the Olympic Games: Relevance, Risks, and Possible Rewards. Sport, Ethics and Philosophy. 6(2), 108-122.

22. THOMPSON, K. \& C. M. MATHESON, 2007. Culture, authenticity and sport: a study of event motivations at the Ulaanbaatar Naadam Festival, Mongolia. In: J. Cochrane. Asian Tourism: Growth and Change. Elsevier, London, pp. 233-244. ISBN: 978-0-08-045356-9. 
23. WEISS, P., 1982. Some philosophical approaches to sport. Journal of the Philosophy of Sport. 9(1), 90-93. 